\title{
Trabalhadores negros na origem da política social brasileira
}

Black laborers at the beginning of Brazilian social policies Gracyelle Costa*

\begin{abstract}
Resumo - A origem da política social no Brasil tem sido atrelada a três segmentos de trabalhadores: ferroviários, marítimos e portuários. A proposta deste artigo é identificar a composição étnica e racial destes segmentos entre o século XIX e início do XX, evidenciando os trabalhadores negros. Além disso, a pesquisa bibliográfica no campo da história social do trabalho foi orientada por metodologia qualitativa. A conclusão atesta a significativa presença dos trabalhadores negros, bem como de suas próprias formas de proteção e sociabilidade afrodiaspóricas, sua organização sindical e o significado das primeiras formas institucionais de política social.

Palavras-chave: política social; trabalhadores negros; previdência social; raça; etnia.

Abstract - The origins of social policy in Brazil has been linked to three segments of workers: rail, sea, and port. The purpose of this paper is to identify the ethnic and racial composition of these segments between the nineteenth and early twentieth centuries, highlighting black workers. The bibliographical research in the field of Social History of work was guided by qualitative methodology. The conclusion attests to the significant presence of black workers, their own forms of social protection and African Diasporic sociability; their union organization and the meaning of the first institutional forms of social policy.
\end{abstract}

Keywords: social policy; Black laborers; social insurance; race in Brazil; ethnicity.

\footnotetext{
*Assistente Social. Doutora em Serviço Social na Universidade do Estado do Rio de Janeiro. Professora na Escola de Serviço Social da Universidade Federal do Rio de Janeiro. E-mail: gracyelle.costa@ess.ufrj.br. ORCID: https://orcid.org/ 0000-0001-6985-9807.
} 


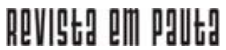

\} TRABALHADORES NEGROS - COSTA, G. \}

DOI: $10.12957 /$ REP.2020.51982

\section{Introdução}

O simultâneo aniquilamento de corpos, saberes e memórias foi fundamental na construção do mundo moderno. Sua análise seria parcial, porém, sem a compreensão do papel da hierarquização racial neste processo, algo ainda presente na divisão internacional do trabalho, nas desigualdades socioeconômicas, no poder político e na produção de conhecimento.

O samba-enredo da escola de samba Estação Primeira de Mangueira, vencedor do carnaval carioca de 2019, mostrou a importância de revisitar a História diante da ascensão do conservadorismo. Nas últimas décadas ações afirmativas têm tornado instituições de ensino superior minimamente plurais, e a Academia tem sido provocada a recuperar histórias até então não contadas. Isso inclui ir além da História Oficial, na qual pessoas negras figuram ainda como meros objetos de pesquisa, tal qual criticou Guerreiro Ramos (1957). Com este espírito surge a proposta aqui sumariada que compõe a primeira parte de uma tese de doutorado'.

Importantes intelectuais que tratam da origem da política social no Brasil vinculam seu surgimento às Caixas e Institutos de Aposentadoria e Pensões (CAPs e IAPs). Depois desses marcos, segundo tal interpretação, o acesso a aposentadorias, pensões, cuidados à saúde (medicamentos, hospitais, atendimento médico), alimentação, habitação, auxílio funeral etc. tornou-se direito social provido institucionalmente (SILVA; MAHAR, 1974; MALLOY, 1986; FALEIROS, 2000; SILVA, 2011; BEHRING; BOSCHETTI, 2011).

Tendo isso em vista, ao estudar que a Lei Eloy Chaves beneficiou ferroviários, marítimos e portuários com aposentadorias e pensões, quantos imaginam estes sujeitos como negros e liderando atividades grevistas com milhares de companheiros também negros? Ou que, antes disso, já organizavam seus próprios métodos de garantia de proteção e cuidados coletivos? A omissão da condição racial destes sujeitos e grupos tende a produzir seu entendimento como brancos. Além disso, as declarações nas quais a condição racial é explícita comumente ressaltam uma brancura originalmente europeia.

Este artigo se dedica, por meio de análise qualitativa, a apresentar aspectos que revelam a presença negra entre os trabalhadores que primeiro acessaram a política social no Brasil. Analisa também a repercussão deste pertencimento em organizações coletivas afro-diaspóricas dos próprios

\footnotetext{
${ }^{1}$ A tese foi dividida em três capítulos. O primeiro, considerado neste artigo, trata da origem da política social no Brasil e da afirmação da presença de trabalhadores negros entre os primeiros segmentos atendidos pelas CAPs e IAPs. O segundo, se dedica à negação da originalidade desta política social institucional, apresentando a diáspora africana nas Américas e os variados laços de solidariedade e proteção social recriados por africanos e afro-descendentes. O terceiro, se dedica à negação da negação e apresenta o caráter específico da política social institucional no início do século XX no país e sua articulação ao projeto de nação e das concepções de raça, eugenia e culturalismo (COSTA, 2020).
} 


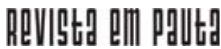

\} TRABALHADORES NEGROS - COSTA, G. \}

DOI: $10.12957 / R E P .2020 .51982$

trabalhadores e na relação com seus empregadores, a partir da experiência dos portuários do Rio de Janeiro do século XIX ao início do XX.

\section{Portuários, marítimos e ferroviários: negros?}

Como mencionado, a origem da política social no Brasil tem sido atrelada às CAPs e IAPs, cuja legitimação é posta pelo Estado através da chamada Lei Eloy Chaves no início do século XX (SILVA; MAHAR, 1974; MALLOY, 1986; FALEIROS, 2000; SILVA, 2011; BEHRING; BOSCHETTI, 2011). Ademais, a legislação brasileira que previu as CAPs teve influência latino-americana, especificamente argentina (MALLOY, 1986). Assim, o processo de institucionalização desse sistema ocorreu em meio à intensa mobilização de trabalhadores no país e no mundo, que resultou em tratados e acordos internacionais.

O Decreto-Legislativo no 4.682 , de 24/01/1923, instituiu a obrigatoriedade das CAPs a ferroviários, estendida através do Decreto n. 5.109, de 20/12/1926, a portuários e marítimos. De 1933 em diante, sob o governo varguista, as Caixas foram aos poucos substituídas por IAPs. Em termos gerais, a gestão, o financiamento e o usufruto das Caixas se restringiam à unidade da empresa (pública ou privada) e aos seus trabalhadores. Já os IAPs, vinculados ao Ministério do Trabalho, Indústria e Comércio, ampliaram a participação e o controle do Estado na gestão dos recursos, ${ }^{2}$ e as categorias profissionais de cada instituto foram consideradas a nível nacional (SILVA; MAHAR, 1974). Ambas as formas, porém, preservaram a perspectiva da solidariedade entre contribuintes e beneficiários: todos contribuem para usufruto de todos.

A proeminência de ferroviários, marítimos e portuários como pioneiros no acesso a esta lógica securitária, como regra, tem sido relacionada com seu papel econômico estratégico numa economia agroexportadora. Sua história, porém, está longe de ser explicada apenas nestes termos. A trajetória das atividades marítimas, ferroviárias e portuárias no Brasil do XIX possui pontos de contato significativos diante de um projeto de sociedade que tomou os meios de transporte como condutores do país ao "progresso"3: 1) a dinamização alinhada ao aumento da exportação e produção de bens primários; 2) o emprego de mão de obra cativa, livre e liberta. Será concedida atenção a este último ponto, mesmo que brevemente, privilegiando a experiência negra entre estes segmentos nos períodos pré e Pós-Abolição (1888).

\footnotetext{
${ }^{2}$ Somente com a Constituição Federal de 1934 a contribuição se deu entre empresas, trabalhadores e União, momento em que CAPs e IAPs coexistiam (SILVA; MAHAR, 1974).

${ }^{3}$ É sabido que no processo de produção capitalista o setor de transportes atua produtivamente, ou seja, produz valor (e mais-valor), mesmo dentro da esfera de circulação (MARX, 2014). O investimento de capital inglês no setor de transportes em países das Americas foi apontado por Luxemburgo (1970).
} 


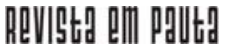

\} TRABALHADORES NEGROS - COSTA, G. \}

DOI: $10.12957 /$ REP.2020.51982

O historiador Robério Souza (2007) identificou a presença de livres, libertos e escravizados nacionais e estrangeiros na construção da primeira ferrovia da Bahia, que ligou o interior do sertão baiano à capital, Salvador, a Bahia and San Francisco Railway Company (BSFR), inaugurada em 1860. Segundo Lamounier (2000), nesta companhia os nacionais foram maioria, o que Souza (2007) complementa indicando entre estes uma predominância negra. Muitos deles, concentrados nas "turmas" responsáveis pela construção das linhas ferroviárias, antes e depois da Abolição, foram contratados por empreitada ${ }^{4}$ e com baixos proventos (SOUZA, 2007; LAMOUNIER, 2008).

No século XIX a Marinha de Guerra, chamada de Armada Imperial, recorria ao "recrutamento" compulsório de indígenas, africanos e afrodescendentes escravizados, bem como de livres "vadios", para composição de mão de obra ${ }^{5}$. Outra estratégia da Armada foi a criação de escolas de aprendizes para treinamento de jovens órfãos e carentes (OLIVEIRA, 2013), uma maioria negra, no caso do Rio de Janeiro, que se manteve mesmo após a Abolição. As formas de recrutamento da mão de obra da Armada Imperial abrem caminhos para se identificar os trabalhadores da Marinha Mercante, sobretudo devido à cessão de mão de obra da própria Armada para a Mercante. Além disso, a própria Mercante fazia uso de mão de obra escravizada, o que a Armada deixou de fazer em dado momento.

Sobre a composição racial dos marítimos no Rio de Janeiro, no fim do século XIX, Cruz (2000, p. 271) afirma que:

Na dinâmica colonial, a imposição dos padrões civilizatórios eurocêntricos pelos grupos dominantes não foi impingida sem que houvesse resistência dos grupos dominados. Muito pelo contrário, a memória da Diáspora Negra não só traz a marca da escravidão, como também das lutas de negação desse padrão de sociabilidade (ALMEIDA, 2014, p. 141). Segundo os mapas estatísticos da Capitania do Porto do Rio de Janeiro, no ano de 1865, 47,5\% da tripulação das embarcações de cabotagem matriculadas na província eram constituídos por homens brancos e 52,5\% por homens de cor. Dos brancos, $72 \%$ eram estrangeiros, e dos pretos e pardos, $80,2 \%$ eram escravos. O tráfego interno do porto e a pesca ocupavam, por sua vez, 908 brancos (26\%), sendo $88,8 \%$ estrangeiros, e 2.591 pretos e pardos $(74 \%)$, dos quais $90,2 \%$ eram escravos.

Em regiões como Rio Grande (RS), Oliveira (2013) identificou o uso de trabalhadores negros escravizados, livres e libertos nessas atividades. Lamounier (2008, p. 7), por sua vez, afirma que "no Brasil, no setor de

\footnotetext{
${ }^{4}$ Sobre isso, importa também dizer que a reedição da Lei Eloy Chaves de 1926 (Decreto-Lei no 5.109), no artigo 2, ratificou sua extensão a estes trabalhadores ao explicitar os jornaleiros e diaristas como componentes da categoria "ferroviários".

${ }^{5}$ É oportuno indicar que este trabalho (e a legislação de Eloy Chaves), ao se referir a "marítimos", está tratando dos trabalhadores da Marinha Mercante, que diferem e se relacionam, de certo modo, daqueles da Armada Imperial Brasileira (Marinha de Guerra).
} 


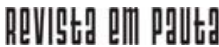

\} TRABALHADORES NEGROS - COSTA, G. \}

DOI: $10.12957 / R E P .2020 .51982$

transportes, os escravos eram empregados nas tropas de mulas, na marinha mercante e nas companhias de navegação de cabotagem". É possível supor que, como nas atividades ferroviárias, as empresas marítimas contratavam quantidades consideráveis de escravizados africanos e afrodescendentes, libertos e livres (nacionais ou não).

Entre os portuários, o exemplo do Rio de Janeiro denota uma maioria de trabalhadores negros nesse período. No maior porto do país nos oitocentos, o segmento negro, entre cativos e libertos, predominou nessas atividades na zona portuária carioca e se notabilizou pelas formas de realização do trabalho e de organização coletiva para preservação de seus interesses (MATTOS, 2010). Esta organização se dava em grupos, que ficaram conhecidos como "cantos", turmas ou tropas. Estes grupos se reuniam por territórios e eram regidos por um líder, também negro (livre, liberto ou escravizado), cujo nome varia no tempo e espaço - capataz, capitão de "canto", feitor, capitão, puxador etc. Sua liderança se expressava tanto ao empreitar o trabalho, quanto ao deliberar tarefas e negociar com contratantes $^{6}$. O trabalho era realizado ao som de cantos africanos entoados pelo grupo (REIS, 1996; CRUZ, 2000; ARANTES, 2010; MCPHEE, 2014). Na Bahia, João José Reis (1993) demonstra que a quantidade de escravizados ao ganho, de maioria nagô, encarregados de serviços de transportes, era também considerável na cidade de Salvador. O ritmo e a maneira de conduzir os trabalhos também eram similares.

Nos três casos, entre o trabalho nas ferrovias, Marinha Mercante ou no porto, os escravizados poderiam pertencer aos empresários ou às companhias, mas também ser por eles alugados na modalidade ao ganho ${ }^{7}$, que no cenário urbano foi muito comum. Por meio da organização dos portuários cariocas será possível observar dois pontos aqui relevantes. Primeiro, suas formas de organização afro-diaspóricas, baseadas na solidariedade com vistas à autoproteção. E, segundo, a permanência destes trabaIhadores negros, a incidência deste pertencimento racial para compreensão de sua organização na República, e como a política social inicialmente é acessada por este grupo.

\section{Laços de solidariedade e proteção afro-diaspóricas no porto do Rio de Janeiro}

James Malloy (1986, p. 49-50) adverte que, antes da Lei Eloy Chaves, "vários tipos de pensões foram esquematizados no período colonial, especialmente a instituição conhecida como Montepio (fundos de seguro

\footnotetext{
${ }^{6}$ Os mesmos nomes (turmas, capataz), modalidade de contratação e negociação aparecem entre os ferroviários. 7 Nesta modalidade de escravização, senhores/as permitiam uma relação de relativa mobilidade territorial para desempenho de atividades laborais realizadas em troca de pecúlios. Eram assim instados/as a sustentar a si e à senhoria ao lhe entregar (diária ou semanalmente) quantias pré-determinadas, sob pena de severas punições quando não alcançadas. Os homens eram nomeados ganhadores, as mulheres ganhadeiras (REIS, 1996; CRUZZ, 2000).
} 


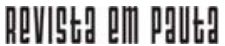

\} TRABALHADORES NEGROS - COSTA, G. \}

DOI: $10.12957 /$ REP.2020.51982

financiados pelo governo)". No país, algumas empresas e companhias privadas antes de 1923, inclusive no setor de transportes, também já adotavam a criação de fundos e caixas beneficentes para os trabalhadores. Os próprios trabalhadores se organizavam em torno de sociedades e associações de auxílio mútuo, fundos, corporações, associações de profissionais, irmandades etc. (MATTOS, 2008). Algumas dessas formas foram recriadas pela população negra em diáspora como espaços de solidariedade, proteção e sociabilidade. A experiência dos portuários no Rio de Janeiro revela alguns destes aspectos.

A condição de viver em diáspora exigiu a conjugação de laços de solidariedade e constituição de formas de proteção coletivas entre africanos e afrodescendentes. A noção de diáspora inicialmente remete à dispersão secular primeiro de gregos e depois de judeus pelo mundo, devido a sistemáticas perseguições ${ }^{8}$. Nas últimas décadas esta noção tem sido também utilizada por ativistas e pesquisadores/as para explicar a migração forçada de africanos iniciada no século XV em territórios colonizados. A violência colonial produzida por segmentos brancos europeus criou as condições para a emergência do capitalismo. É sabido que o tráfico, a comercialização e escravização de pessoas do Continente Africano nas Américas e Caribe foram elementares para transformar traficantes em industriais na Inglaterra, como explicou Eric Williams (2012). Pensar nos termos da diáspora implica reconhecer a violência genocida produzida pelo deslocamento sem, ao mesmo tempo, desconsiderar que a população africana, de diversas etnias, reconstituiu-se enquanto sujeitos e reconstruíram territórios sob outras perspectivas.

[...] mesmo em uma realidade adversa, os negros africanos e seus descendentes não tiveram outra opção senão lutar para sobreviver aos abusos a que foram submetidos. Na dinâmica colonial, a imposição dos padrões civilizatórios eurocêntricos pelos grupos dominantes não foi impingida sem que houvesse resistência dos grupos dominados. Muito pelo contrário, a memória da Diáspora Negra não só traz a marca da escravidão, como também das lutas de negação desse padrão de sociabilidade. (ALMEIDA, 2014, p. 141).

Reconhecer a diáspora significa conferir a estes, que do processo colonial em diante passaram a ser chamados de negros, um lugar na história como sujeitos. Elementos únicos foram produzidos na diáspora, sejam culturais, religiosos, protetivos ou político-organizativos. O aquilombamento, a proteção autogestada via religiões de matriz africanas e irmandades, dentre outras, foram fundamentais diante de um cenário, no mínimo, hostil. Na cidade do Rio de Janeiro não foi diferente e será considerada a partir da experiência dos minas no porto.

${ }^{8}$ Encyclopedia Britannica (2019). 


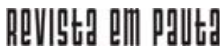

\} TRABALHADORES NEGROS - COSTA, G. \}

DOI: $10.12957 / R E P .2020 .51982$

A presença mina na composição dos trabalhadores do porto carioca tem sido comprovada desde o século XIX por viajantes e pesquisadores/ as. Todas as pessoas africanas que forçosamente embarcaram na chamada "Costa da Mina", região do atual Golfo do Benin, receberam a nomeação genérica de "mina" ou "nação mina". Segundo Mariza Soares (2000), a depender do período, a denominação "mina" poderia remeter a diferentes grupos étnicos. Distintas etnias falantes de língua iorubá na Bahia, chamadas de nagôs, foram classificadas como minas, ao mesmo tempo que etnias falantes da língua ewé também o foram. Ser mina na cidade do Rio de Janeiro do XVIII poderia estar mais ligado aos falantes de ewé, conhecidos na Bahia como jeje. Mas ser mina no XIX poderia também remeter aos povos iorubás advindos da Bahia com o fortalecimento do tráfico interprovincial, dado o aumento da produção cafeeira no Sudeste e o fim do tráfico transatlântico.

A cidade carioca teve, contudo, uma composição africana de maioria advinda das regiões da África Ocidental, sobretudo de CongoAngola, grupos étnicos distintos que no Brasil foram chamados de "bantos". Eram eles, por exemplo, a maioria entre os escravizados ao ganho registrados na Câmara Municipal do Rio de Janeiro entre 1851 e 1870 (CRUZ, 2000). Mesmo assim, elementos tendem a reforçar a relevância da presença mina em algumas atividades.

No porto, por exemplo, o "canto" entre os minas foi espaço de associação de auxílio mútuo, adquirindo a função de consórcio entre os membros daquele grupo (CUNHA, 1985; ARANTES, 2010). Os minas e sua organização coletiva chamaram a atenção de viajantes franceses, como Jean-Baptiste Debret e Charles Ribeyrolles, ao visitarem o Rio de Janeiro. Ribeyrolles, entre 1858 e 1861, registrou, como reproduziu Cruz (2000, p. 258), as seguintes observações:

Esses negros que passam, cesto à mão, ou esses outros imóveis aos cantos dos corredores... são pretos do ganho a vossa espera. Percorrem a cidade, as ruas comerciais, as praças públicas... A qualquer hora vergam sob o fardo. Quando este é por demais pesado formam grupo... e lá se vão ao som cadenciado de uma canção breve e triste... Mais além encontramos a rua de São Bento. Grande entreposto de café. Dela, sobretudo, parte os negros minas, atléticos, mármores vivos, que fazem o transporte dos armazéns ao cais. Rebeldes de toda sorte de escravatura doméstica, formam entre si uma corporação, sustentam uma caixa de resgates que a cada ano alforria e remete alguns às plagas africanas.

A proximidade entre os fundos de libertação criados pelos estivadores ${ }^{9}$ africanos e afrodescendentes no porto do Rio foram por mais de uma vez citados como aproximados de uma instituição de crédito iorubá

\footnotetext{
${ }^{9}$ O estivador, segundo o Dicionário Básico Portuário (2019, p. 55), é o “profissional que trabalha na carga e descarga de navios; o que dirige a carga e a descarga de navios por conta própria ou de casa comercial".
} 


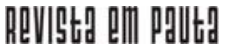

\} TRABALHADORES NEGROS - COSTA, G. \}

DOI: $10.12957 /$ REP.2020.51982

chamada esusu (CRUZ, 2000; ARANTES, 2010). A esusu manifestou-se em outras regiões das Américas, mas suas raízes se vinculam à região da atual Nigéria. Em grupos, formavam um fundo em comum com contribuições periódicas em quantia fixada previamente. Em revezamento, cada um podia usufruir de determinada quantia, e o uso era pessoal (BASCOM, 1952). A contribuição era coletiva e o usufruto partilhado. Nas Américas, a esusu assumiu um caráter afro-diaspórico e seu sentido se transformou. A compra da liberdade, de passagens de retorno para o Continente Africano, por exemplo, eram alguns dos novos sentidos dados ao agrupamento de pecúlio com os mesmos fins. Eram práticas de solidariedade econômica e social autogovernadas $^{10}$.

Se fosse aventada a hipótese de que os fundos criados no "canto" fossem restritos aos minas-iorubás, poder-se ia dizer que entre os minasewé as irmandades constituíram seu espaço de proteção autogestada. Elas existiam na tradição européia desde o século XII ligadas a profissões e heranças pagãs. Vinculadas a paróquias, mas organizadas por leigos, centravam sua prática em filantropia, apoio em caso de doenças e mortes, mas também em festividades. A partir do século XVII as irmandades leigas, também chamadas de confrarias, ocuparam importante papel na disseminação e organização da religiosidade e do poder da Igreja Católica no Brasil colonial (REGINALDO, 2018).

As irmandades tinham, entretanto, certa autonomia e eram regidas por um estatuto, o "compromisso", que definia seus objetivos, meios de ingresso, obrigações e direitos dos membros. Elas eram dirigidas por uma mesa administrativa composta pelos chamados juízes, provedores, tesoureiros, escrivães etc. Podiam ser organizadas por profissões, nacionalidade, pertencimento étnico e racial e giravam em torno de santos/as (REIS, 1996; MATTOS, 2008). Das irmandades leigas, a mais conhecida no país foi a da Misericórdia, constituída por membros da elite branca, o que lhe conferia status e volumosos recursos financeiros (BOSCHI, 1986).

$\mathrm{Na}$ diáspora, as irmandades foram ressignificadas. Instadas como instrumento de dominação portuguesa para cristianização de escravizados por meio de santos negros, elas foram aos poucos se moldando como espaços de resistência de escravizados e libertos. No limite de tal contradição, as irmandades negras foram espaços de aglutinação, solidariedade, ligação com o sagrado, em diálogo direto com referências ancestrais do Continente Africano. Suas intervenções variaram desde a compra da liberdade, o cuidado com os ritos na hora da morte e os festejos, até a participação em processos abolicionistas (MATTOS, 2008; REGINALDO, 2018; PINTO, 2003).

\footnotetext{
${ }^{10}$ Como explicado em Hossein (2018), nas Américas, entre outros povos africanos, práticas com este sentido também foram identificadas.
} 


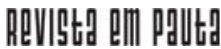

\} TRABALHADORES NEGROS - COSTA, G. \}

DOI: $10.12957 / R E P .2020 .51982$

No Rio de Janeiro, entre 1753 e 1852, foram localizadas 24 irmandades negras ligadas a 12 igrejas (MATTOS, 2008), e é nesta cidade que está localizado um dos compromissos (estatutos) mais antigos do Brasil, o da Irmandade da Nossa Senhora do Rosário, de 1639 (REGINALDO, 2018), cujos devotos eram sobretudo da África Central. Segundo Reis (1996), embora entre os negros da cidade do Rio de Janeiro predominassem os grupos étnicos advindos da África Central e Austral, as irmandades tiveram destaque entre os minas. Além disso, Mariza Soares (2000) demonstra a sólida organização dos minas falantes de ewé, especificamente os da etnia maki, na construção da Irmandade de Santo Elesbão e Santa Ephigênia no Rio desde o XVIII.

\section{União e Resistência no século XX: trabalhadores negros na origem da política social}

A região da zona portuária (hoje Gamboa, Saúde, Santo Cristo, Praça Onze) foi significativamente habitada e transitada por sujeitos negros mesmo após a Abolição de 1888, e recebeu o apelido de "Pequena África". Um franco contraste à Europa dos Trópicos desejada pelas elites (MATTOS, 2008), para quem não bastava se livrar do status colonial (1822), se fazer Império e abolir a Escravidão (1888); era preciso dar vida às teorias racialistas e seguir o norte do progresso europeu por meio da imigração europeia e do estímulo à miscigenação, mirando o branqueamento da nação (MUNANGA, 1999). A eugenia teve papel decisivo nesse processo e se manifestou inclusive na política social e nas ideias culturalistas que anunciavam a suposta harmonização das raças no país ${ }^{11}$. Por seu turno, um ideal de trabalhador foi moldado e exaltado, em termos morais e raciais, pelo que foi chamado de trabalhismo (GOMES, 1988). Este ideal ainda é emulado em análises sobre conquistas de direitos e participação política de trabalhadores no início do XX. Como os portuários da época revelam resistências a este processo?

Nos primeiros anos do século XX uma série de eventos marcou a organização dos portuários cariocas, segmento que permaneceu majoritariamente negro ${ }^{12}$ Pós-Abolição (CRUZ, 2000), recuperando referências anteriores e se aliando a outras, como as socialistas. Esses sindicatos ocuparam papel crucial e exigiam a filiação dos trabalhadores. Os capitães de outrora se forjaram fiscais, as empresas se dirigiam aos representantes dos trabalhadores e a exclusividade (monopólio) na contratação de sindicalizados passou a ser chamada de closed shop.

\footnotetext{
${ }^{11}$ Questão detalhada no capítulo 3 da referida tese de doutorado.

${ }^{12}$ Para Cruz (2000), mesmo com o aumento da imigração no porto e no mar do Rio esta composição se manteve.
} 


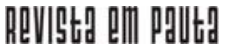

\} TRABALHADORES NEGROS - COSTA, G. \}

DOI: $10.12957 /$ REP.2020.51982

Em 1903 foi fundada a União dos Estivadores, mesmo ano da Sociedade Regeneradora Beneficente dos Estivadores, e, em 1905, a Sociedade de Resistência dos Trabalhadores em Trapiche e Café, conhecida, segundo Galvão (1995), como Companhia dos Pretos, esta última criada com o apoio da União. A União dos Operários Estivadores, cujo primeiro presidente era negro (ALMEIDA, 2003), adotava apenas a nacionalidade e não a raça/cor como quesito em suas fichas; nas localizadas entre 1903 e 1905, totalizaram 811 sindicalizados. Ainda assim, Cruz (2000) identificou que a maioria dos sindicalizados na União também eram negros.

A autora comparou os dados de nacionalidade da União com os dos livros de registros da Casa de Detenção de 1890 a 1904, onde foram localizados 294 estivadores presos designados por cor e nacionalidade: $60 \%$ pretos, pardos e fulos; $7 \%$ morenos; $28 \%$ brancos e 3\% acaboclados, nos termos da época. Organização pioneira na República entre os portuários negros, a União dos Operários Estivadores mantinha sua propria Caixa, como Almeida (2003) registrou e Oliveira (2014, p. 41) descreveu:

A organização da União dos Operários Estivadores era de cunho sindical e tinha por um dos objetivos as questões referentes a regularização do serviço, a remuneração mais adequada, etc. Entretanto, ainda tinha muito das associações mutualistas de autoproteção características do século XIX. A entidade, preservava ainda características de socorro mútuo entre os membros, visando lhes garantir, caso faltasse, serviço e ajuda em caso de enfermidades e morte do associado.

Com base nos arquivos e registros sindicais da Resistência, de 1910 a 1929, Cruz (2000) registrou o perfil étnico-racial dos sindicalizados, cerca de 353 no total. Assim, 62\% deles eram pretos (entre estes, apenas um africano), $14 \%$ pardos/mestiços (brasileiros) e $23 \%$ brancos (italianos e portugueses). Também é sabido que os trabalhadores negros ocuparam, entre 1910 e 1929, 83,1\% dos cargos administrativos da Resistência (MCPHEE, 2014). No tocante à nacionalidade, $87 \%$ eram brasileiros, $7 \%$ portugueses e 5\% italianos (CRUZ, 2000).

Os conflitos com outros sindicalizados brancos de outras nacionalidades foram frequentes, mas, segundo Cruz (2006), isso não reduziu a força destas organizações. Em relação aos empregadores, a condição racial também se manifestou ante a pontos cruciais para os trabalhadores, especialmente nos conflitos a respeito do closed shop. O monopólio de mão de obra garantido pelos sindicatos, ainda que se mostrasse favorável aos empregadores (que não se preocupavam com o recrutamento), também o era, em alguma medida, para os trabalhadores, considerando o contexto de hostilidade contra a população negra. Uma conquista após a greve portuária de 1906, com mais de três mil portuários, demonstrou isso.

Como os próprios carregadores anunciaram em manifestos espalhados na região portuária, em dezembro de 1906, o que eles almejavam 
com a greve era 'o direito' e 'a nossa liberdade', ou seja, não serem mais vistos como 'negrada', isto é, como 'libertos', mas como homens que eram livres no sentido forte da expressão. (CRUZ, 2000, p. 288).

Ao mesmo tempo, a reação de empregadores ao crescimento dos sindicatos negros se baseava no racismo. A declaração de um empregador ao Jornal do Commercio, em 1908, diante de outro acordo com termos similares ao anterior, expressa essa percepção:

Esse acordo é motivo da maior vergonha para todos nós e, se implementado, sinalizará o triunfo da Resistência, composta de nada além de trabalhadores boçais, sobre os empreendedores do setor mais importante em nossa sociedade [...] devemos continuar a trabalhar dessa maneira quando nossa constituição garante a liberdade de mão de obra e os benefícios da imigração cada vez mais numerosa? (MCPHEE, 2014, p. 288).

Sobre o aumento da imigração neste período, o Sindicato da Resistência não estava alheio à explícita tentativa de substituição de força de trabalho, especialmente no mercado formal. Assim, deliberou em suas assembleias por agir tanto com financiamentos para criação e impressão de propagandas para divulgação em países da Europa sobre os perigos e condições da imigração no Brasil, quanto subsidiando viagens de retorno de imigrantes filiados ao sindicato que desejassem voltar às suas terras (MCPHEE, 2014). A União e a Resistência combinaram solidariedade racial e de classe em seus atos.

Mas em 1918, após intensa greve com cerca de dois mil trabaIhadores reivindicando a manutenção do closed shop, houve um resultado inesperado. Os empregadores, com apoio do Estado, em lugar de ceder às exigências dos trabalhadores, Ihes concederam uma Caixa Beneficente. Esta Caixa, formada com recursos de exportadores do setor cafeeiro carioca, tinha como finalidade prover pensões e cuidados à saúde dos trabalhadores. Com esta aparente derrota dos trabalhadores negros a greve acabou. Assim, a greve de 1918 expôs os sindicatos de portuários aos limites que são próprios das relações capitalistas.

Como se veio a saber, o presidente não havia concedido aos trabalhadores poder absoluto sobre a contratação sem garantir algum incentivo concreto para que os membros do sindicato aceitassem os princípios do trabalho livre. Isso ficou claro vários dias depois. A principal iniciativa foi a fundação de uma caixa beneficente para proteger os trabalhadores em caso de doença; uma porção dela seria pago pelos exportadores e comissários. Porém, e mais importante, o benefício só seria concedido àqueles que concordassem com o poder absoluto dos patrões sobre seu emprego nos armazéns. Isso refletiu a aceitação de um conjunto de recomendações feitas por um comitê composto por membros do Centro do Commercio de Café, que apresentara a 


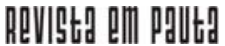

\} TRABALHADORES NEGROS - COSTA, G. \}

DOI: $10.12957 /$ REP.2020.51982

ideia de um fundo de pensão ao presidente republicano e ao chefe de polícia da cidade. A principal demanda era a de que os fiscais perdessem o controle sobre o emprego de trabalhadores sindicalizados nos armazéns ou no transporte. (MCPHEE, 2014, p. 300).

A contradição desta conquista é expressa no próprio nome da Caixa, que será então constituída Caixa Beneficente dos Trabalhadores Livres [do serviço do café] do Porto Carioca. Em 2 de setembro de 1918, a assembleia convocada pelo Centro de Commercio foi noticiada. Ali, os representantes de firmas e negociantes de café compuseram uma comissão para elaboração, deliberação e homologação dos termos e diretrizes da Caixa pelo Centro do Commercio de Café. Ao final, formou-se também uma comissão encarregada da elaboração de um estatuto e outra para estabelecimento do capital para formação da Caixa. Trabalhadores não compuseram este processo. Nas falas dos empregadores e legisladores foram registradas a criminalização da Resistência.

A princípio, o primeiro investimento sobre a Caixa coube a alguns empregadores do setor e seria investido na compra de títulos da dívida pública $^{13}$, com vistas a seu rendimento. Contudo, posto o baixo valor, concluiu-se que os ganhos seriam reduzidos. Sendo assim, exportadores e recebedores envolvidos no ciclo cafeeiro pagariam uma taxa por saca de café para prover os fundos da Caixa.

Respeitadas as particularidades, esta Caixa foi uma certa prévia do que seria constituído em todos os portuários do Brasil apenas em 1926, com a extensão da Lei Eloy Chaves a marítimos e portuários. De todo modo, ela reforça a indicação de Malloy sobre a criação deste tipo de fundos pelas companhias privadas. Por outro lado, a União ilustrou sua indicação sobre as iniciativas dos próprios trabalhadores, o que, como foi demonstrado entre os portuários do Rio, possui história prévia de raízes afro-diaspóricas.

Uma derrota para os portuários negros? Sim e não. Estes trabalhadores produziram não só um modo de organizar o trabalho, como também um relacionar-se em comunidade e denunciar não apenas as injustiças pertinentes à condição de trabalhador, mas também de apontar a discriminação étnico-racial. Além disso, produziram particularidades no modo de ser deste segmento na diáspora. Ilustrativa desta importância foi a própria Resistência:

A Resistência fez muito para mudar a escravização dos trabalhadores. Era muito comum que, sob o menor pretexto, um trabalhador fosse punido com uma chicotada sem ninguém para defendê-la. 'Açoitem o negro', eles costumavam gritar, e ninguém se importava [...] A Resistência era como um dique em uma torrente de perversidade que nós construímos para nossa proteção. A Resistência nos deu um

${ }^{13}$ Afinal, essa não é uma novidade para o capital financeiro. 
novo 13 de maio, um novo conjunto de direitos. (MCPHEE, 2014, p. 286).

O fazer-se classe no contexto capitalista brasileiro foi sustentado no pertencimento étnico-racial, fosse ou não este acionado de forma explícita. Ademais, os trabalhadores negros do porto carioca, como os da Resistência, tinham entendimento sobre essa conjunção e de seus resultados nas relações cotidianas. Raça, nação e nativismo compunham muitas vezes os embates e mediações envolvendo Estado, trabalhadores e empregadores. Assim, cada grupo construiu relativa apropriação destes termos em seus discursos e ações, a partir de suas experiências concretas, em tentativa de realização de seus interesses.

Esta é uma amostra da complexidade de fatores que envolveram uma primeira aproximação dos portuários a prévias da política social, organizada por empregadores sob chancela estatal. Ainda que atendesse a interesses históricos da categoria, sua conquista veio atrelada à tentativa de dissolução de sua própria identidade social-coletiva em termos raciais e de classe.

\section{Considerações que não podem ser finais}

A organização dos portuários cariocas foi fundamental não apenas em termos de classe, mas na constituição de uma solidariedade étnica e racial num contexto de intenso racismo. Por fim, importa reconhecer que conquistas como políticas sociais, mesmo com crucial relevância - pois modificam em determinado grau as condições coletivas de vida e trabalho de quem as reivindica - não alteram o quadro de fundo que as produz e que os repõe como sujeitos que vivem para o trabalho. Contudo, compreender a relevância e o grau de radicalidade possível da mutualidade manifesta pelos fundos de libertação, esusus, Irmandades negras e seus vínculos possíveis com os sindicatos após a Abolição, como forma de manutenção da solidariedade em termos de raça e classe entre os estivadores negros cariocas, implica o entendimento da diáspora africana. Ademais, exige, sobretudo a adoção de uma concepção antirracista da história da política social, ir além de análises que buscam mimetismos da Europa e observar a realidade, estabelecendo as devidas mediações entre a realidade local e global. Isso implica reconhecer que na origem da política social brasileira a população negra se fez presente, nos termos de Almeida (2009), também como "sujeito histórico", a despeito dos processos criados no âmbito da sociedade e reproduzidos por mecanismos institucionais para impedimento da própria existência da população negra.

Estes portuários negros, como argumenta Erika Arantes (2010), desenvolveram formas de sociabilidade próprias, todas elas sustentadas em 


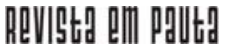

\} TRABALHADORES NEGROS - COSTA, G. \}

DOI: $10.12957 /$ REP.2020.51982

religiões de matriz africana e em festividades católicas, como a Festa da Penha, onde eram inaugurados e avaliados os sambas para o carnaval das escolas de samba. Portuários negros sindicalizados podiam ser Ogãs e sambistas, como foram João da Baiana e Mano Elói, demonstrando a complexidade que envolve a vida desses trabalhadores. O Sindicato da Resistência continuou firme por anos e seus sindicalizados, ainda com maioria negra, fundaram em 1940 o Grêmio Recreativo Escola de Samba Império Serrano, expressando a força afro-diaspórica. Tudo isso foi protagonizado por aqueles que têm sido meramente citados episodicamente na história da política social brasileira ou mesmo vêm passando em branco. 


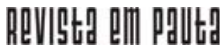

\} TRABALHADORES NEGROS - COSTA, G. \}

DOI: $10.12957 /$ REP.2020.51982

\section{Referências}

ALMEIDA, M. S. Das Irmandades negras dos séculos XVII

a XIX às políticas sociais contemporâneas: uma necessária reflexão sobre a invisibilidade do negro como sujeito histórico. In: BABAWALE, T. et al. (Orgs). Teaching and propagating African and diaspora history and culture. Centre for Black and African Arts and Civilization, 2009. p. 817- 833.

ALMEIDA, M. S. Desumanização da população negra: genocídio como princípio tácito do capitalismo. Revista Em Pauta, Rio de Janeiro, v. 12, n. 34, 2014.

ALMEIDA, L. G. N. Estivadores do Rio de Janeiro: um século de presença na história do movimento operário brasileiro. Rio de Janeiro: Topbooks Editora, 2003.

ARANTES, E. O porto negro: trabalho, cultura e associativismo dos trabalhadores portuários no Rio de Janeiro na virada do XIX para o XX. 2010. 223 f. Tese (Doutorado em História) - Universidade Federal Fluminense, Rio de Janeiro, 2010.

BASCOM, W. The Esusu. A credit institution of the yoruba. The Journal of the Royal Antropological Institute of Great Britain and Ireland, v. 82, n. 1, jan./jun., 1952.

BEHRING, E. R.; BOSCHETTI, I. Política social: fundamentos e história. São Paulo: Cortez, 2011.

BOSCHI, C. C. Os leigos e o poder. Irmandades negras e política colonizadora em Minas Gerais. São Paulo: Editora Ática, 1986.

BRASIL. Decreto no 4.682, de 24 de Janeiro de 1923. Crea, em cada uma das emprezas de estradas de ferro existentes no paiz, uma caixa de aposentadoria e pensões para os respectivos ernpregados (sic.). Disponível em: https:// www2.camara.leg.br. Acesso em: 03 mar. 2018.

BRASIL. Decreto n. 5.109, de 20 de dezembro de 1926. Estende o regimen do decreto legislativo n. 4.682, de 24 de janeiro de 1923, a outras emprezas (sic.). Disponível em: https://www2.camara.leg.br. Acesso em: 09 mai. 2018.

COSTA, G. Raça e nação na origem da política social brasileira: União e Resistência dos trabalhadores negros. 2020. 309f. (Doutorado em Serviço Social). Faculdade de Serviço Social. Universidade do Estado do Rio de Janeiro, Rio de Janeiro, 2020.

CRUZ, M. C. Tradições negras na formação de um sindicato: sociedade de resistência dos trabalhadores em trapiche e café, Rio de Janeiro, 19051930. Revista Afro-Ásia, n. 24, 2000. 


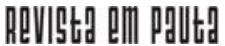

\} TRABALHADORES NEGROS - COSTA, G. \}

DOI: $10.12957 /$ REP.2020.51982

CUNHA, M. C. Negros, estrangeiros: os escravos libertos e sua volta à África. São Paulo: Brasiliense, 1985.

DICIONÁRIO Básico Portuário . 3 ed. Administração dos Portos de Paraná; Governo do Estado do Paraná. 2019.

ENCYCLOPEDIA Britannica. Diaspora. Disponível em: https://www.brita nnica.com/topic/diaspora-social-science. Acesso em: set. 2019.

FALEIROS, V. de P. A política social do Estado capitalista. São Paulo: Cortez, 2000.

GALVÃO, O. M. R. A Sociedade de resistência ou Companhia dos Pretos: um estudo de caso entre os arrumadores do Porto do Rio de Janeiro. 1994. Dissertação (Mestrado em Ciências Sociais), Instituto de Filosofia e Ciências Sociais, Universidade Federal do Rio de Janeiro, Rio de Janeiro, 1994.

GOMES, A. C. A invenção do trabalhismo. São Paulo: Vértice, Editora Revista dos Tribunais; Rio de Janeiro: Instituto Universitário de Pesquisas do Rio de Janeiro, 1988.

HOSSEIN, C. S. (ed.). The Black social economy in the Americas: exploring diverse community-based markets. New York: College of Staten Island, 2018.

LAMOUNIER, M. L. Ferrovias agricultura de exportação e mão de obra no Brasil no século XIX. Revista História Econômica \& História de Empresas III, 2000.

LAMOUNIER, M. L. Entre a escravidão e o trabalho livre. Escravos e imigrantes nas obras de construção das ferrovias no Brasil no século XIX. In: ENCONTRO NACIONAL DE ECONOMIA, 36, 2008.

LUXEMBURGO, R. A acumulação do capital: estudo sobre a interpretação econômica do imperialismo. Rio de Janeiro: Zahar Editores, 1970.

MALLOY, J. M. A política da Previdência Social no Brasil. Rio de Janeiro: Edições Graal, 1986.

MATTOS, M. B. Escravizados e livres: experiências comuns na formação da classe trabalhadora carioca. Rio de Janeiro: Bom Texto, 2008.

MATTOS, M. B. Recuando no tempo e avançando na análise: novas questões para os estudos sobre a formação da classe trabalhadora no Brasil. In: MATTOS, M. B. et al. (org.). Faces do trabalho: escravizados e livres. Rio de Janeiro: Eduff, 2010.

MARX, K. O capital. Livro I. São Paulo: Boitempo, 2014.

MCPHEE, K. Um novo 13 de maio: trabalhadores portuários afro-brasileiros no Rio de Janeiro, 1905-1918. In: GOMES, F.; DOMINGUES, P. (org.). Políticas da raça: experiências e legados da abolição e da pós-emancipação no Brasil. São Paulo: Selo Negro Edições, 2014. 


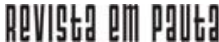

\} TRABALHADORES NEGROS - COSTA, G. \}

DOI: $10.12957 / R E P .2020 .51982$

MUNANGA, K. Rediscutindo a mestiçagem no Brasil: identidade nacional versus identidade negra. Petrópolis: Vozes, 1999.

OLIVEIRA, V. P. de. Sobre águas revoltas: cultura política maruja na cidade portuária de Rio Grande/RS (1835 a 1864). Tese (Doutorado em História) - Programa de Pós-Graduação em História, Universidade Federal do Rio Grande do Sul, Rio Grande do Sul, 2013.

OLIVEIRA, G. S. C. Experiências e solidariedade na formação da União dos Operários Estivadores (Rio de Janeiro, 1903-1910). Trabalho de Conclusão de Curso (Licenciatura em História) - Instituto Multidisciplinar, Universidade Federal Rural do Rio de Janeiro, Nova Iguaçu, 2014.

PINTO, E. A. O Serviço Social e a questão étnico-racial: um estudo de sua relação com usuários negros. São Paulo: Terceira Margem, 2003.

RAMOS, G. Introdução crítica à sociologia brasileira. Rio de Janeiro: Editorial Andes Ltda., 1957.

REGINALDO, L. Irmandades. In: SCHWARCZ, L. M.; GOMES, F. (org.). Dicionário da escravidão e liberdade: 50 textos críticos. São Paulo: Companhia das Letras, 2018.

REIS, J. J. Identidade e diversidade étnicas nas irmandades negras no tempo da escravidão. Revista Tempo, Rio de Janeiro, v. 2, n. 3, 1996.

SILVA, F. A. R.; MAHAR, D. Saúde e Previdência Social: uma análise econômica. Rio de Janeiro: Ipea/Inpes, 1974.

SILVA, M. L. L. da. (Des)estruturação do trabalho e condições para a universalização da Previdência Social no Brasil. Tese (Doutorado em Política Social) - Programa de Pós-Graduação em Política Social, UnB, Brasília, 2011.

SOARES, M. C. Devotos da cor. Rio de Janeiro: Civilização Brasileira, 2000.

SOUZA, R. S. Experiências de trabalhadores nos caminhos de ferro da Bahia: trabalho, solidariedade e conflitos (1892-1909). 2007. 147f. Dissertação (Mestrado em História) - Instituto de Filosofia e Ciências Humanas, Universidade Estadual de Campinas, Campinas, SP, 2007.

WILLIAMS, E. Capitalismo \& escravidão. São Paulo: Companhia das Letras, 2012.

DOI: $10.12957 /$ rep.2020.51982

Recebido em 21 de julho de 2019.

Aprovado para publicação em 20 de novembro de 2019.

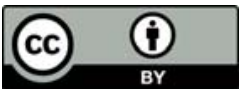

A Revista Em Pauta: Teoria Social e Realidade Contemporânea está licenciada com uma Licença Creative Commons Atribuição 4.0 Internacional. 